\title{
HPLC-MS analysis of the active ingredients of chamomile (Matricaria chamomilla) bee feeding syrup
}

\author{
${ }^{1}$ Éva Nagy $-{ }^{2}$ József Jekő - ${ }^{2}$ Zoltán Cziáky $-{ }^{3}$ Lajos Daróczi $-{ }^{1}$ András Jávor \\ ${ }^{1}$ University of Debrecen Faculty of Agricultural and Food Sciences and Environmental Management, \\ Institute of Animal Science, Biotechnology and Nature Conservation, Debrecen, Hungary \\ ${ }^{2}$ College of Nyíregyháza, Institute of Environmental Science, Nyíregyháza, Hungary \\ ${ }^{3}$ Y-Food Ltd., Berettyóújfalu, Hungary \\ nagy.eva@agr.unideb.hu
}

\section{SUMMARY}

\begin{abstract}
Apiarists let prepare by bee honey products containing medicinal drugs. Our aim was to prove that the active ingredients originated from the herbs are also present in the bee products. This publication focuses only to the chamomile (Matricaria chamomilla) containing feeding syrup and the difference between the various syrup phases. To fulfil this task, we developed a method analysing the non-volatile components of the syrup using the flowers of chamomile. The method involves a filtration followed by HPLC-MS analysis. The analyses and the data evaluations proved that the non-volatile components of the herb were transferred to syrup. As the characteristic components of certain herbs could be identified also in the syrup, it is obvious that the components responsible for the medicinal effects are also transferred.
\end{abstract}

Keywords: chamomile, herbs, honey, bee product, honey keeper, liquid chromatography, mass spectrometry, HPLC-MS

\section{INTRODUCTION}

The use of the natural medicine ingredients was suppressed for a while because the development of the modern techniques. However, nowadays the demand increases; more and more people try to recover and keep their health with the help of those natural medicines. The novel recently discovered panaceas still cannot overshadow those medicinal drugs which are used for thousands of years by the traditional medicine like different honeys and herbals.

There are lots of medicinal plants as nectar source but there are several other useful herbals which cannot serve as nectar source. There are lots of handbooks known about medicinal plants and their use which contains detailed scientific description of the different plants and their effect (Ody 1993, Schönfelder and Schönfelder 2005, Csupor and Szendrei 2012).

Apiarists at Berettyóújfalu have got an idea to feed the bees with extracts of medicinal plants to improve their health. They reached more benefit as they planed because the bees became healthier and stronger and they produced a product with similar taste and colour to the herbal was feed. Therefore, it is obvious that the components responsible for the medicinal effects are also transferred to bee product. With this procedure they could combine the beneficial effects of honey and herbs on natural way (Szalay and Halmágyi 1998, Molan 1999, Sáfián 2012, Darócz 2014).

To feeding the bees the beekeepers prepared syrup enriched with the extract of herbs according to appropriate recipes. Therefore, it is important that the trade of this product as honey is not allowed but those honey products are labelled as "MORETHANHONEY" (in Hungarian: „TÖBBMINTMÉZ”). The feeding syrup preparation consist the following steps (Sáfián 2012):

1. Blend of herb and sugar,

2. Basic juice: selection of herb and sugar,
3. Fermented juice: fermentation of plant residue with apple vinegar,

4. Feeding Syrup: basic juice+ fermented juice+ sugar+ water,

5. Bee product: from feeding syrup with the mediate of bees.

The aim of our studies was to compare the compound of different syrup phases in chase of chamomile. There were two tasks in our research: on one hand to identify the non-volatile components of syrup with high performance liquid chromatographymass spectrometry (HPLC-MS) and on the other hand to make difference between the different syrup phases to improve the work of beekeepers. By means of the analysis of non-volatile component compositions we can determine the similarity of the herbs; the syrup was made from herbs, and the final bee product. The analysis of the non-volatile components a solid phase extraction (SPE) sample preparation method followed by HPLC-MS analysis is recommended (Michalkiewicz et al. 2008). The aim of the present study was the analysis only of the non-volatile components in feeding syrup.

\section{MATERIALS AND METHODS}

\section{Samples}

This year beekeepers used seven different medicinal plants for feeding bees: chamomile (Matricaria recutita) nettle (Urtica dioica), sea buckthorn (Hippophae rhamnoides), rosehip (Rosa canina), sage (Salvia officinalis), ragweed (Ambrosia artemisiifolia), green walnut (Juglans regia). In this publication we only focus on chamomile, it is shown is Table 1. Based on the results of chamomile is presumable that the other plants ingredients show similar transformation through the syrup making steps. 
The syrup preparation process includes three different steps. In the following they are called syrup phases.

1. Basic juice: selection of herb and sugar.
2. Fermented juice: fermentation of plant residue with apple vinegar.

3. Feeding Syrup: basic juice+ fermented juice+ sugar+ water.

Applied herb and type of syrup phase

\begin{tabular}{|c|c|c|c|}
\hline Herbs & Latin name & Used parts & Syrup phases \\
\hline Chamomile & Matricaria chamomilla & Flowers & $\begin{array}{c}\text { Basic juice } \\
\text { Fermented juice } \\
\text { Syrup }\end{array}$ \\
\hline
\end{tabular}

\section{Sample preparation}

In the first period we applied an SPE extraction followed by HPLC-MS analysis (Michalkiewicz et al. 2008).

In this method we applied an ISOLUTE C18 (500 $\mathrm{mg} / 3 \mathrm{ml}$ ) column.

Picture 1 shows the sample preparation steps:

1. Homogenization of samples, heat to $40{ }^{\circ} \mathrm{C}$ if needed,

2. Conditioning: $2 \mathrm{ml}$ ethyl-acetate, $2 \mathrm{ml}$ ethanol: water mixture (60:40), $2 \mathrm{ml}$ distilled water,
3. Dilute $5 \mathrm{~g}$ sample with $10 \mathrm{ml}$ distilled water, filtrate with $0.45 \mu \mathrm{m}$ micro filter, send $5 \mathrm{ml}$ to column,

4. Wash with $2 \mathrm{ml}$ distilled water,

5. Dry the phase with argon,

6. Wash with $2 \mathrm{ml}$ ethyl-acetate, collect fraction to $1.5 \mathrm{ml}$ sample vial,

7. Dry the phase with argon,

8. Wash with $2 \mathrm{ml} 0.01 \%$ hydrochloric acid methanol solution, collect fraction to $1.5 \mathrm{ml}$ sample vial.

\section{Picture 1: SPE sample preparation steps}

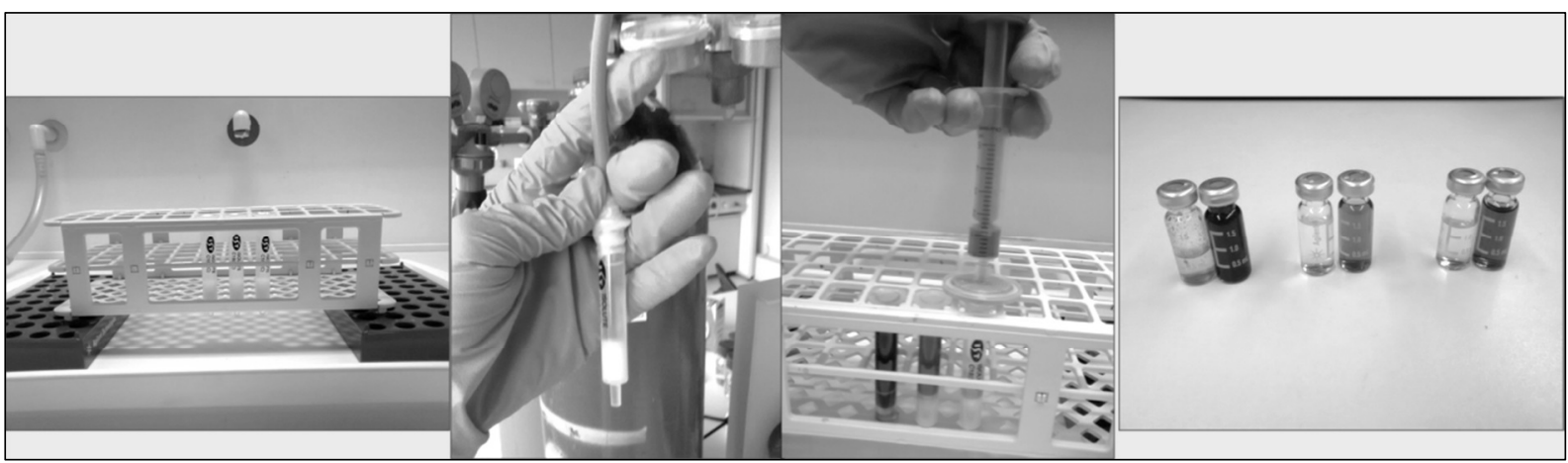

This method was very time-consuming and worked with less efficiency due to the high degree of dilution. After HPLC-MS analysis chromatograms were hard to evaluate because of the low concentration of single components. Owing to the modern HPLC-MS equipment this complicated method can be eliminated.

In the second period we used a simple microfiltration (PALL Acrodisc $32 \mathrm{~mm}$ Syringe filter with 0.45 um Supor Membrane ) to prepare the syrupy samples.

Sample preparation steps were the following:
1. Homogenization of the samples, heat $40{ }^{\circ} \mathrm{C}$ if needed,

2. The homogenized sample is sucked in to a syringe,

3. The filter is connected to the syringe,

4. The sample is pushed from the syringe through the filter,

5. Filtered sample is collected to a $1.5 \mathrm{ml}$ sample vial.

The HPLC-MS analyses were performed on a Thermo UltiMate ${ }^{\mathrm{TM}} 3000$ liquid-chromatograph connected with Thermo Q Exactive Mass spectrometer (Table 2). 
HPLC-MS method parameters

\begin{tabular}{ll}
\hline \multicolumn{1}{c}{ LC parameters } & \multicolumn{1}{c}{ MS parameters } \\
\hline Eluent: & Ion source type: HESI \\
B: $\mathrm{H}_{2} \mathrm{O}+0.1 \% \mathrm{FA}$ & Polarity: positive/negative \\
C: $\mathrm{MeOH}+0.1 \% \mathrm{FA}$ & Scan type: Full MS \\
Column: Agilent Eclipse XDB-C18 $(150 \mathrm{~mm} \times 4,6 \mathrm{~mm} \times \mathrm{ID} 5 \mu \mathrm{m})$ & Scan range: $100-1500 \mathrm{~m} / \mathrm{z}$ \\
Gradient: & Resolution: 35000 \\
$0.2 \mathrm{ml} / \mathrm{min}$ & Spray voltage $+: 4.5 \mathrm{kV}$ \\
$0-43 \mathrm{~min} » \mathrm{~B}: \mathrm{C}=95 \%: 5 \%$ & Spray voltage $-: 3.3 \mathrm{kV}$ \\
$43-62 \mathrm{~min} » \mathrm{C}=100 \%$ & Capillary temp.: $320{ }^{\circ} \mathrm{C}$ \\
$62-70 \mathrm{~min} » \mathrm{~B}: \mathrm{C}=95 \%: 5 \%$ & Probe heather temp.: $300{ }^{\circ} \mathrm{C}$ \\
Temperature: $25{ }^{\circ} \mathrm{C}$ & \\
Injection volume: $5 \mu 1$ & \\
Detection: $280 \mathrm{~nm}$ & \\
Control software: Agilent ChemStation (A.10.02) & \\
\hline
\end{tabular}

\section{RESULTS}

The purpose of the study is not the quantification; we focused only on quality determination. The following Table 3 shows the surely identified molecules. Most of them are flavonoids and have antioxidant effect.

Identified compounds

\begin{tabular}{lccc}
\hline \multicolumn{1}{c}{ Compound } & CAS & Type & Effect \\
\hline 1 Pantothetic acid (B5 vitamin) & $599-54-2$ & amide & vitamine \\
2 Chlorogenic acid & $327-97-9$ & poliphenol ester & antioxidant, anti-inflammatory \\
3 Umbelliferone & $93-35-6$ & cumarine & antioxidant \\
4 Indolelactic acid & $832-97-3$ & indole derivative & no information \\
5 Taxifoline & $480-18-2$ & flavonoide & chemopreventive \\
6 Isoquercitrin & $482-35-9$ & flavonoide & antioxidant \\
7 Herniarin & $531-59-9$ & cumarine derivative & antifungal, antibiotical \\
8 Izorhamnetin-3-O-glucoside & $5041-82-7$ & flavonoide & antioxidant, antihypertensive \\
9 Luteolin & $491-70-3$ & flavonoide & antioxidant \\
10 Apigenin (Chamomile) & $520-36-5$ & flavonoide & chemopreventive
\end{tabular}

Figure 1 shows the proportion of identified compounds between syrup phases by area. The main component of chamomile is herniarin which has antifungal and antimicrobial effect. The other important compound is apigenin. This is also called chamomile and it has chemo preventive role (Spinella 2001).

Figure 2 shows the overlaid total ion chromatograms (TIC) of chamomile feeding syrup in positive and negative mass spectrometric mode. To compare and overlay the TIC of different syrup phases it is easy to see that here is no big difference between them. It is also supported by Figure 1 .

\section{DISCUSSION}

Our aim was to prove that the active ingredients originated from the herbs are also present in the bee products. We only focused to qualify the compounds and not to quantify them. This publication focus only to the chamomile (Matricaria chamomilla) containing feeding syrup and the difference between the syrup phases.

To fulfill that task, we developed a method analyzing the non-volatile components of the syrup using the flowers of chamomile. The method involved a filtration followed by HPLC-MS analysis. The analyses and the data evaluations proved that the nonvolatile components of the herb were transferred to syrup. The results show that there is no significant difference between the different syrup phases. Based on these results, beekeepers can develop the method of syrup preparation. As the characteristic components of certain herbs could be identified also in the syrup it is obvious that the components responsible for the medicinal effects are also transferred.

The presented results of the measurements confirm the assumption, that the components of the herb were transferred to the feeding syrup. The honey products made in this way are useful medicines and contain the compounds which are responsible for the medicinal effect like other products (e.g. tee) made from the original herbs. 
Figure 1: Proportion of identified compounds between syrup phases by area

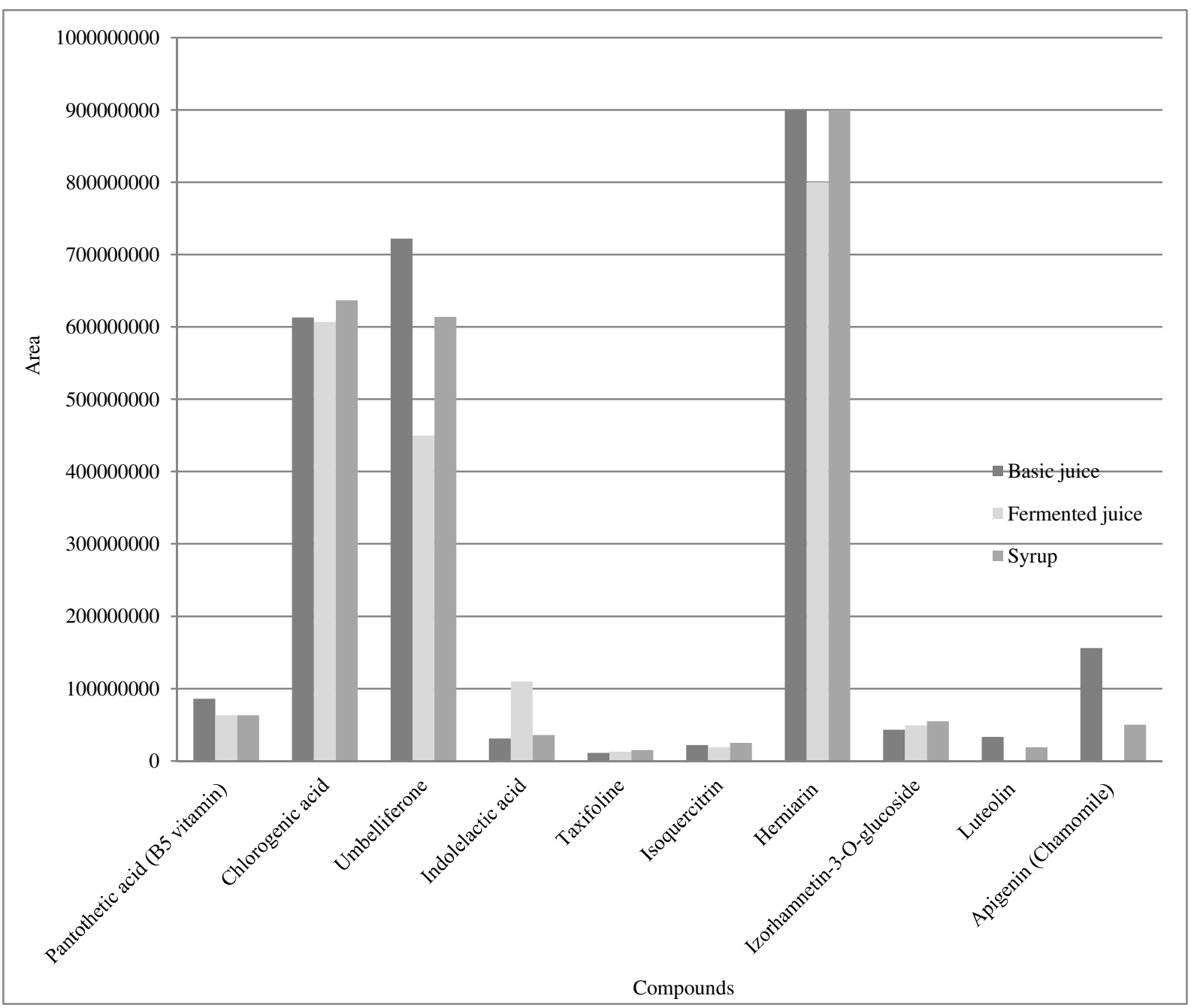

Figure 2: Chamomile syrup overlayed positive and negative total ion chromatogram

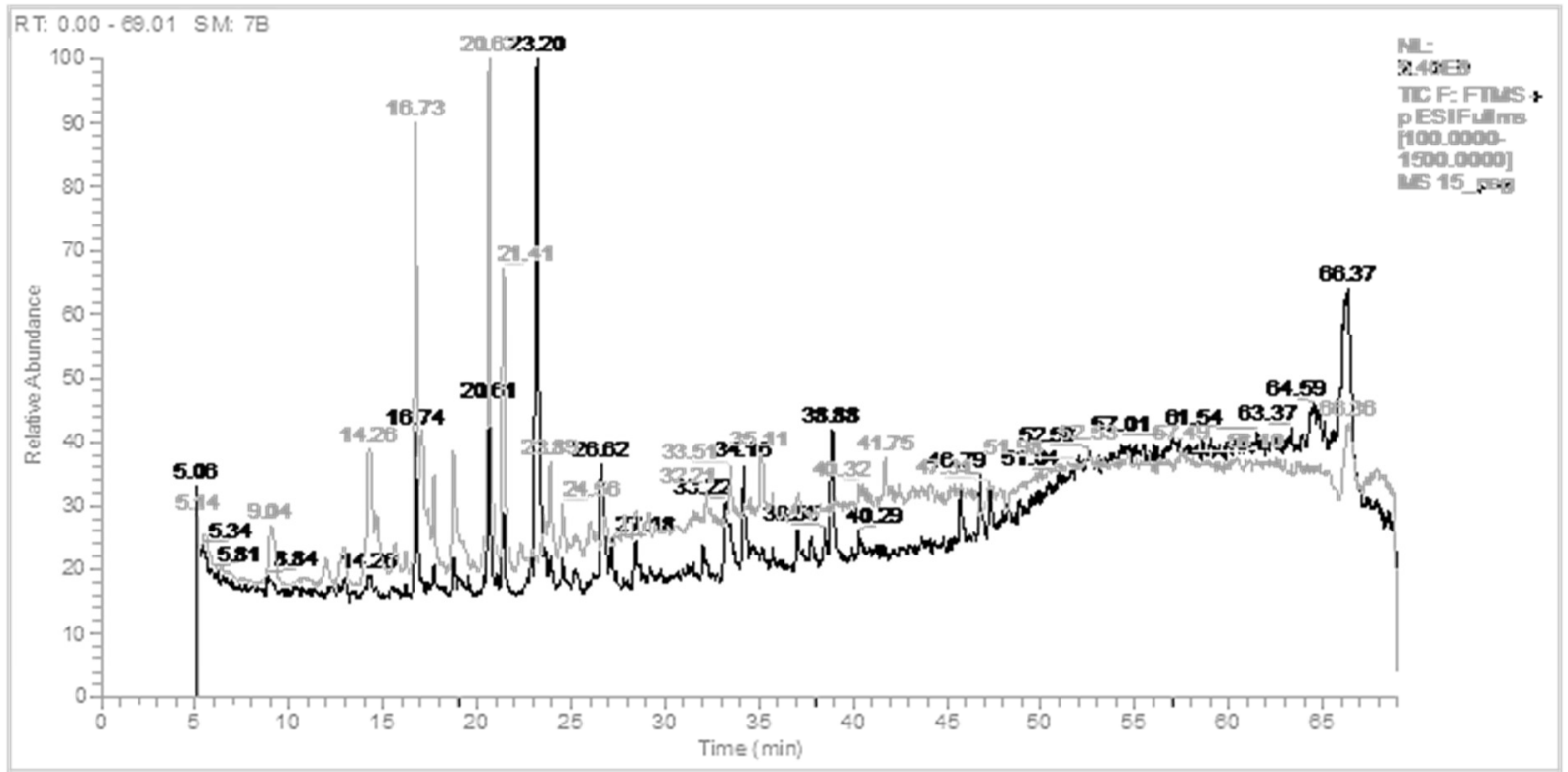


ACKNOWLEDGEMENTS

The publication is supported by the EFOP-3.6.3VEKOP-16-2017-00008 project. The project is co- financed by the European Union and the European Social Found.

\section{REFERENCES}

Csupor D.-Szendrei K. (2012): Gyógynövénytár-útmutató a korszerü gyógynövény alkalmazáshoz. 2. kiadás. Medicina Könyvkiadó Zrt. Budapest.

Daróczi L. (2014): (Personal communication)

Michalkiewicz, A. -Biesaga, M. -Pyrzynska, K. (2008): Solidphase extraction procedure for determination of phenolic acids and some flavonols in honey. Journal of Chromatography A. 1187. 1-2: 18-24.

Molan, P. (1999): Why honey is effective as a medicine I. Its use in modern medicine. Bee World. 80. 2: 80-92.

Ody, P. (1993): The complete medicinal herbal A practical guide to the healing properties of herbs, with more then 250 remedies for common ailments. Idaho Youth Ranch Books. Boise. ID. USA.
Sáfián J. (2012): Méhek etetése gyógynövény tartalmú takarmánnyal. (Personal communication)

Schönfelder I.-Schönfelder P. (2005): Gyógynövényhatározó. Holló és társa Kft. Kaposvár.

Szalay L.-Halmágyi L. (1998): Gyógyító mézek és mézelő gyógynövények. Magyar Méhészek Egyesülete. Budapest.

Spinella, M. (2001): The Psychopharmacology of Herbal Medicine: Plant Drugs That Alter Mind, Brain and Behavior. The MIT Press. Cambridge. MA. 